\title{
The effects of gadolinium, a stretch-sensitive channel blocker, on diaphragm muscle
}

\author{
C. Coirault*, M-P. Sauviat*, D. Chemla**, J-C. Pourny*, Y. Lecarpentier**
}

\begin{abstract}
The effects of gadolinium, a stretch-sensitive channel blocker, on diaphragm muscle. C. Coirault, M-P. Sauviat, D. Chemla, J-C. Pourny, Y. Lecarpentier (C)ERS Journals Ltd 1999. ABSTRACT: Stretch-activated channels (SAC) have been identified in many cell types including striated muscles. In diaphragm muscle, the influence of SAC on the length-active tension relationship remains unknown.

Patch clamp experiments were performed on single fibres $(n=10)$. In isolated diaphragm muscle from adult hamsters, the effects of gadolinium $\left(\mathrm{Gd}^{3+}\right)$, the most potent inhibitor of SAC blocker, on tension response to stretch at baseline were studied $(n=10)$, after pretreatment of the muscle with $1 \mathrm{nmol}$ isoproterenol $(\mathrm{n}=10), 0.5$ $\mu$ mol forskolin $(\mathrm{n}=6)$, or $0.1 \mathrm{mmol}$ dibutyryl cyclic adenosine monophosphate (cAMP) $(n=10)$. Results were compared to those obtained in low $\left[\mathrm{Na}^{+}\right]_{\mathrm{e}}(\mathrm{n}=10), \mathrm{Ca}^{2+}$-free medium $(n=6)$ or after $5 \mu$ mol nifedipine $(n=8)$.

$\mathrm{Gd}^{3+}$ reduced active tension measured over a range of initial muscle lengths in a concentration-dependent manner $(10$ and $50 \mu \mathrm{mol})$. In isolated fibres, mechanical stretch generated a membrane current that was sensitive to $\mathrm{Gd}^{3+}$. In muscles, lowering $\left[\mathrm{Na}^{+}\right]_{e}$ mimicked the effects of $\mathrm{Gd}^{3+}$, while no change in the length-tension relationship was observed in $\mathrm{Ca}^{2+}$-free medium or after nifedipine. Drugs which increase cAMP prevented the effects of $\mathrm{Gd}^{3+}$ on active tension.

In the diaphragm, gadolinium-sensitive channels are activated during physiological changes in length and influence tension development. Moreover, cyclic adenosine monophosphate content modulates the effects of gadolinium on stretch-activated channels.
\end{abstract}

Eur Respir J 1999; 14: 1297-1303.
*U 451 INSERM-Laboratoire d'Optique Appliquée-ENSTA Ecole Polytechnique, 91761 Palaiseau, France **Service d'Explorations Fonctionnelles, Hôpital de Bicetre, Assistance Publique-Hôpitaux de Paris, 94275 Le Kremlin-Bicetre, France

Correspondence: C. Coirault

INSERM 451-LOA-ENSTA Ecole Polytechnique

Batterie de 1'Yvette

91761 Palaiseau Cedex

France

Fax: 33169319996

Keywords: Contractility

initial muscle length

stretch-activated channel

skeletal muscle

Received: March 311999

Accepted after revision August 61999
The diaphragm, the most important inspiratory muscle, has to contract rhythmically throughout life to sustain ventilation. Changes in end-expiratory lung volume and/or in the thoraco-abdominal configuration, such as those which occur during postural changes, modify resting diaphragmatic muscle length [1]. This in turn modulates the contractile performance of the diaphragm according to its initial length-active tension relationship. The cellular basis of the relation between initial length and active tension is that the tension of skeletal muscle fibres is generated by crossbridges which form in the region of overlap between thin and thick filaments [2, 3]. The amount of overlap between these filaments determines the number of crossbridges generating force [3]. Changes in resting muscle length also induce changes in membraneous tension which, in turn, may activate mechanosensitive channels located at the level of the sarcolemma [4]. Mechanosensitive channels have been described in a variety of cells, including skeletal muscle fibres [5, 6]. Most of these stretch-sensitive channels mediates the influx of cations from the extracellular space into the myocyte [7-12]. In skeletal muscles however, the physiological relevance of stretch-sensitive channels is unknown.

It was postulated that changes in initial muscle length activate stretch-sensitive channels in the adult diaphragm and modulate contractility in physiological conditions.
The authors therefore examined the effects of gadolinium $\left(\mathrm{Gd}^{3+}\right)$, the most potent blocker of stretch-activated channels $[8,12]$ on active tension development during physiological length changes in isolated diaphragm muscle from adult hamsters. Moreover, given that stretch induces $\mathrm{Na}^{+}$and/or $\mathrm{Ca}^{2+}$ influx into skeletal and cardiac myocytes, (i.e. $[9,10]$ ). The possibility that $\mathrm{Na}^{+}$and/or $\mathrm{Ca}^{2+}$ influx from the extracellular space was required for stretch modulation of the length-tension curve was considered. This study thus examined whether a reduced extracellular $\mathrm{Na}^{+}$concentration $\left(\left[\mathrm{Na}^{+}\right]_{\mathrm{e}}\right), \mathrm{Ca}^{2+}$-free medium or nifedipine mimicked the effects of $\mathrm{Gd}^{3+}$ on the length-active tension curve. Finally, as activation of the adenylate cyclase cascade has been implicated in the regulation of a number of sarcolemmal ion channels [13, 14], this study also examined the ability of isoproterenol, forskolin and adenosine $3^{\prime}, 5^{\prime}$-cyclic monophosphate (cAMP) to modulate the $\mathrm{Gd}^{3+}$-induced changes in the relation between initial length and active tension.

\section{Materials and methods}

\section{Experimental protocol}

Mechanical study. Experiments were conducted on 60 adult golden hamsters. Care of the animals conformed to 
international guidelines. After pentobarbital sodium anaesthesia (30 mg kg body weight ${ }^{-1}$ intra-peritoneally), the animals were laparotomized then thoracotomized. A strip of the ventral costal diaphragm was carefully removed from the muscle in situ. This diaphragm strip was rapidly mounted in a tissue chamber containing a Krebs-Henseleit solution (in mmol. $\mathrm{L}^{-1}: \mathrm{NaCl} 118, \mathrm{KCl} 4.7, \mathrm{MgSO}_{4}$ 1.2, $\mathrm{KH}_{2} \mathrm{PO}_{4} 1.1, \mathrm{NaHCO}_{3} 24, \mathrm{CaCl}_{2} 2.5$ and glucose 4.5). The solution was maintained at $26^{\circ} \mathrm{C}$ and equilibrated with a $95 \% \mathrm{O}_{2}-5 \% \mathrm{CO}_{2}$ gas mixture, giving a $\mathrm{pH}$ of 7.4. The costal end of the muscle strip was held by a stationary clip at the bottom of the chamber, while the central tendon end was attached to an electromagnetic force-transducer device $[15,16]$. After a 30 -min stabilization period, diaphragm strips were tetanically stimulated by means of two platinum electrodes as follows: stimulation frequency: $50 \mathrm{~Hz}$; train duration: $350 \mathrm{~ms}$; train frequency: $10 \cdot \mathrm{min}^{-1}$; electrical stimulus duration: $1 \mathrm{~ms}$. At $26^{\circ} \mathrm{C}$, the $50 \mathrm{~Hz}$ stimulation frequency provided the maximum isometric tension. A series of isometric contractions generated at incremental initial muscle lengths was used to determine the optimal muscle length (Lo) corresponding to the maximum active force. At the end of the experiment, the cross-sectional area $\left(\mathrm{mm}^{2}\right)$ was calculated from the ratio of muscle weight to muscle length at Lo, assuming a muscle specific gravity of 1.056 .

Study protocol. Control values of maximum isometric tension were first recorded at Lo. Thereafter, initial muscle length $(\mathrm{Li}$, expressed as a percentage of Lo) was set at $85 \%$ Lo and gradually stretched to $115 \%$ Lo with $5 \%$ Lo step intervals. Length changes were performed before each stimulation $\left(10 \cdot \mathrm{min}^{-1}\right)$. Isometric active tension (AT; in $\mathrm{mN} \cdot \mathrm{mm}^{-2}$ ) was recorded immediately after each change in Li so as to obtain the maximal activation of stretch-sensitive channels [9]. Two baseline measurements of the initial lengthactive tension ( $\mathrm{Li}-\mathrm{AT})$ relationship were recorded at a 10-min interval to ensure the stability of the preparation. Thereafter, diaphragm muscle strips were divided into seven groups. In group $1(n=10)$, the effects of cumulative con-centrations of $\mathrm{Gd}^{3+}(10$ and $50 \mu \mathrm{mol})$ on the length-tension curve were studied. In groups 2,3 and 4 , one of the following agents was added to the solution $15 \mathrm{~min}$ before $50 \mu \mathrm{mol} \mathrm{Gd}{ }^{3+}: 1 \mathrm{nmol}$ isoproterenol (group 2, $\mathrm{n}=10$ ), $0.5 \mu \mathrm{mol}$ forskolin (group 3, $\mathrm{n}=$ 6), or $0.1 \mu \mathrm{mol}$ dibutyryl cAMP (dcAMP; group $4, \mathrm{n}=$ 10). Two other separate groups were studied to determine whether changes in extracellular $\mathrm{Na}^{+}$and $\mathrm{Ca}^{2+}$ concentrations mimicked the effects of $\mathrm{Gd}^{3+}$ on the length-tension relationship:in group $5(\mathrm{n}=10)$, the $\left[\mathrm{Na}^{+}\right]_{\mathrm{e}}$ was decreased from 142 to $99 \mathrm{mmol}$. The reduced-Na ${ }^{+}$ solution was made by substitution of sucrose for $\mathrm{NaCl}$ $(1.71 \mathrm{~mol}$ sucrose was used for $1 \mathrm{~mol} \mathrm{NaCl})$; in group $6(\mathrm{n}=6)$, muscles were incubated in $\mathrm{Ca}^{2+}$-free solution containing $0.1 \mathrm{mmol}$ ethyleneglycol - bis - $(\beta$-aminoethylether)-N,N'-tetraacetic acid (EGTA). In group $7(n=8)$, the effects of $5 \mu \mathrm{mol}$ nifedipine on the length-active tension curve were studied. At this concentration, nifedipine has been shown to completely block the slow $\mathrm{Ca}^{2+}$ inward current in skeletal muscle [17]. Forskolin and nifedipine were dissolved in dimethyl sulfoxide, the volume of which did not exceed 1/1,000 ( $\mathrm{vol} / \mathrm{vol})$ of the bath volume. This concentration was selected on the basis of a preliminary study in which $1 / 1,000$ ( $\mathrm{vol} / \mathrm{vol}$ ) dimethyl sulfoxide did not alter length-tension relationships of isolated diaphragm muscle.

In all groups, the relation between $\mathrm{Li}$ and $\mathrm{AT}$ was recorded $15 \mathrm{~min}$ after each change in experimental conditions. To ensure that comparisons of tension values within experimental groups were made at similar levels of relative initial length, each experimental AT versus Li relationship was fitted using a fourth-order polynomial function ( $\mathrm{r}=$ $0.997 \pm 0.001$ (mean \pm SEM). The equations of the fitted curves were entered into a computer using the TransERA HTBasic Advanced Math Library (TransERA Corporation, Provo, UT, USA) which calculated the relative active tension at fixed $\mathrm{Li}$ (i.e.; $\mathrm{Li}=85,90,95,100,105,110$ and $115 \% \mathrm{Lo})$.

Electrophysiological study. Transmembrane resting potentials (RP) and action potentials (AP) were recorded at $26^{\circ} \mathrm{C}$ in isolated diaphragm muscles. Conventional glass microelectrodes $(0.86 \mathrm{~mm}$ ID; Clark Electromedical Instruments, Reading, UK), filled with saturated $\mathrm{KCl}$ (25-30 Mohms resistance; tip potential $\leq \pm 3 \mathrm{mV}$ ) were connected to the input stage of a voltage follower by means of a thin $\mathrm{Ag} \mathrm{AgCl}$ wire. The preparation was electrically driven by square pulses ( $1 \mathrm{~ms}$ duration) delivered at 0.5 $\mathrm{Hz}$ through bipolar platinum electrodes which were earth isolated using an optoelectrometric coupling device [18]. Transmembrane potentials $(n=16$ obtained from five muscles) were displayed and stored on a digital oscilloscope (Nicolet 310; Nicolet Instruments, Plaisin, France).

Patch clamp experiments were performed at room temperature $\left(20-22^{\circ} \mathrm{C}\right)$ on single fibres enzymatically isolated from costal diaphragm segments. After dissection, muscle bundles were allowed to equilibrate for $20 \mathrm{~min}$ in oxygenated $\mathrm{Ca}^{2+}$-free physiological solution containing (in mmol): $\mathrm{NaCl} 137, \mathrm{KCl} 5, \mathrm{MgCl} 21$, glucose 10, Hepes $(\mathrm{NaOH}$ $\mathrm{MgCL}_{2}$ buffer) 10 (pH 7.4). Muscles were then placed for $2 \mathrm{~h}$ at $30^{\circ} \mathrm{C}$ in enzyme solution containing $0.7 \mathrm{mg} \cdot \mathrm{mL}^{-1}$ collagenase (type I; Sigma, France), $0.7 \mathrm{mg} \cdot \mathrm{mL}^{-1}$ papain (Sigma) and $0.7 \mathrm{mg} \cdot \mathrm{mL}^{-1}$ dithiothreitol (Sigma) added to $\mathrm{Ca}^{2+}$ - free saline solution. After isolation, single fibres were immersed in $\mathrm{Ca}^{2+}$ containing physiological solution and studied in cell-attached configuration.

The patch current was monitored using an Axopatch 200B amplifier (Axon Instruments, Foster City, CA, USA). Electrodes (Propper Manufacturing Co, New York, USA; id $1.2 \mathrm{~mm}$, wall $0.2 \mathrm{~mm}$; tip diameter $1.1-1.6 \mathrm{~mm}$ ) were filled with the physiological solution (resistance 1.5-2.5 Mohms). The current signals were filtered at $5 \mathrm{KHz}$ with a 4-pole lowpass Bessel filter. Mechanical stimulation was performed by reducing the pressure inside the patch pipette by applying suction with a syringe coupled to the lumen of the pipette and calibrated with a water manometer. Seal resistance was $\geq 10 \mathrm{Gohms}$. $\mathrm{Gd}^{3+}$ was applied inside the pipette by means of a $3 \mu \mathrm{L}$ micropipette (Drummond Microcaps, Scientific Company, Swedesboro, NJ, USA). Appropriate concentrations of $\mathrm{Gd}^{3+}$ were obtained by diffusion of the drug toward the tip of a pipette. Diaphragm fibres were successively held at various pipette potentials ranging -160-120 mV (incremental steps: $40 \mathrm{mV}$ ). Membrane potentials were calculated on the assumption of an $\mathrm{RP}=-80 \mathrm{mV}$. From conventional intracellular recordings in single isolated fibres, the resting potential was $-79.5 \pm 0.8$ $\mathrm{mV}$ (mean $\pm \mathrm{SEM}, \mathrm{n}=16$ from three muscles). Downward 
deflection from the baseline represented inward current. Membrane currents were recorded with a Labmaster card (DMA 1000EM; Scientific Solutions, Dipsi, Ancueil, France) driven by Acquis1 software and stored on a desk computer (Venex System AT80486 DX33; Venex, Paris, France). Electrophysiological data were analyzed using Sigmaplot (Jandel Scientific GmbH, Erkrath, Germany).

\section{Statistical analysis}

Data are expressed as means \pm SEM. Homogeneity between groups at baseline was tested by using analysis of variance (ANOVA). Within each group, differences between active tension studied at different time points were inferred by using ANOVA with a repeated-measures design followed, if appropriate, by Student's t-test with the Bonferroni correction. The influence of $\mathrm{Li}$ on the reduction in active tension after $\mathrm{Gd}^{3+}$ addition and/or $\left[\mathrm{Na}^{+}\right]_{\mathrm{e}}$ reduction was tested using ANOVA. A p-value of $<0.05$ was considered statistically significant.

\section{Results}

Relation between diaphragm initial length and active tension at baseline

At $50 \mathrm{~Hz}$ stimulation frequency, AT increased from $139.7 \pm 3.6 \mathrm{mN} \cdot \mathrm{mm}^{-2}$ at $85 \%$ Lo to $173.3 \pm 2.2 \mathrm{mN} \cdot \mathrm{mm}^{-2}$ at Lo, and then declined with subsequent increases in $\mathrm{Li}$ to $110.8 \pm 3.0 \mathrm{mN} \cdot \mathrm{mm}^{-2}$ at $115 \%$ Lo $(\mathrm{n}=60)$. All the groups were comparable as regards the baseline Li versus AT relationship.

Effects of $\mathrm{Gd}^{3+}$ on the relation between initial length and active tension

$\mathrm{Gd}^{3+}$ downward shifted the relation between Li and AT (group $1, \mathrm{n}=10$ ) in a concentration-dependent manner from 10-50 $\mu \mathrm{mol}$ (fig. 1a). Whatever the $\mathrm{Gd}^{3+}$ concentration, there was no change in Lo, i.e., the length at which the maximum peak tension was measured. The negative inotropic effect of $\mathrm{Gd}^{3+}$ was quantified at each Li by measuring the absolute decrease in AT, which depended on the initial muscle length $(\mathrm{p}<0.05)$ (fig. $1 \mathrm{~b}): \mathrm{Gd}^{3+}$ had a marked negative inotropic effect at the shortest initial lengths, but only a moderate effect at lengths above Lo.

\section{Electrophysiological recordings}

Figure 2a shows typical evoked action potentials (AP) recorded in isolated diaphragm muscles before and after $50 \mu \mathrm{mol} \mathrm{Gd} \mathrm{d}^{3+}$ treatment. In the absence of stretch, $\mathrm{Gd}^{3+}$ did not modify the resting potential and the parameters (derivative of the initial depolarizing phase, overshoot, and duration) of the AP (table 1). Figure 2b depicts representative membrane current recorded with normal saline solution in the bath. At a membrane potential of -80 $\mathrm{mV}$, suction generated an inward current which disappeared upon removal of the suction (fig. 2b). The amplitude of the current increased with enhanced negative pressure, to $40 \pm 4 \mathrm{pA}$ at a pulse suction of $-5 \mathrm{mmH}_{2} \mathrm{O}$ and tending towards its maximum value $(58 \pm 6 \mathrm{pA})$ at -20 $\mathrm{mmH}_{2} \mathrm{O}(\mathrm{n}=4)$. The stretch-induced current elicited at -80
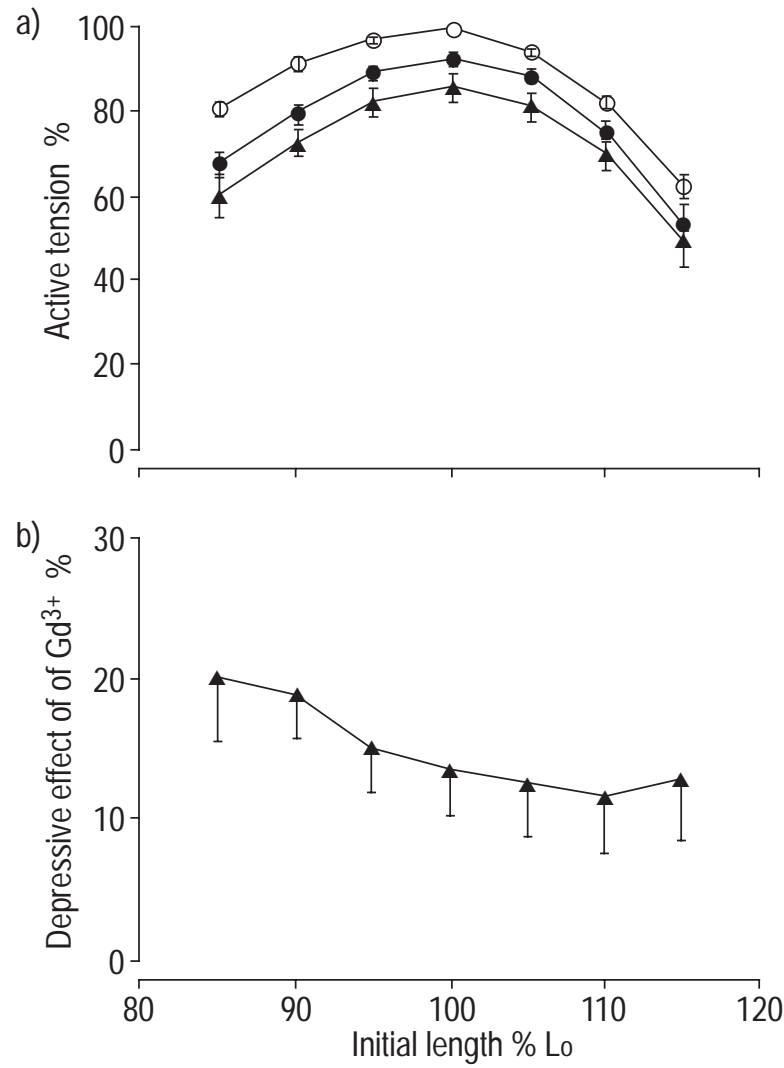

Fig. 1. - a) Effects of cumulative concentrations of $\mathrm{Gd}^{3+}(10$ and 50 $\mu \mathrm{mol})$ on the relation between initial length $(\mathrm{Li})$ and active tension (AT) of isolated diaphragm muscle from adult hamsters. $\mathrm{Gd}^{3+}$ depressed tetanic AT in a concentration-dependent manner. b) absolute decrease in AT after $50 \mu \mathrm{mol} \mathrm{Gd}{ }^{3+}$ as a function of $\mathrm{Li}$. For each $\mathrm{Li}$, the depressive effect of $\mathrm{Gd}^{3+}$ was defined as baseline AT minus AT after $\mathrm{Gd}^{3+}$. The depressive effect of $\mathrm{Gd}^{3+}$ predominated at the shortest $\mathrm{Li}$, pointing to a length-dependent effect of $\mathrm{Gd}^{3+}$. Values are mean \pm SEM $(n=10)$. $\bigcirc$ : baseline; : $\mathrm{Gd}^{3+} 10 \mu \mathrm{mol}$. $\boldsymbol{\Delta}: \mathrm{Gd}^{3+} 50 \mu \mathrm{mol} . \mathrm{p}<0.05$, as compared to baseline. Lo: optimal muscle length.

$\mathrm{mV}$ by a pulse suction of $-20 \mathrm{mmH}_{2} \mathrm{O}$ was reduced by $51 \pm 5 \%$ in the presence of $10 \mu \mathrm{mol} \mathrm{Gd}{ }^{3+}(\mathrm{n}=12)$ and completely blocked by $50 \mu \mathrm{mol} \mathrm{Gd}{ }^{3+}$ (fig. $2 \mathrm{c}$ ). Currentvoltage relationships induced at $-20 \mathrm{mmH}_{2} \mathrm{O}$ are presented in figure $2 d(n=6)$. Mean amplitude of the current varied with membrane potential (fig. $2 \mathrm{~d}$ ). Whatever the membrane potential investigated, $50 \mu \mathrm{mol} \mathrm{Gd^{3+ }}$ completely abolished the stretch-induced current (figs. $2 \mathrm{c}$ and $2 \mathrm{~d}$ ). The apparent reversal potential of the stretch-induced current, taken as the intersection of the curves obtained before and after $\mathrm{Gd}^{3+}$ (fig. 2d) was $32 \pm 2.6 \mathrm{mV}$.

\section{Effects of activating the adenylate cyclase cascade}

Isoproterenol $(1 \mathrm{nmol})$, forskolin $(0.5 \mu \mathrm{mol})$ and dcAMP $(0.1 \mathrm{mmol})$ alone did not significantly modify the baseline Li versus AT relationship (fig. 3). Prior treatment with isoproterenol (group 2) prevented the effects of $\mathrm{Gd}^{3+}$ on the $\mathrm{Li}$ versus AT relationship (fig. 3a). Likewise, pretreatment of the muscle with either forskolin (group 3) or dcAMP (group 4) prevented the effects of $\mathrm{Gd}^{3+}$ on the relation between initial length and active tension (figs. $3 \mathrm{~b}$ and $3 \mathrm{c}$ ). 

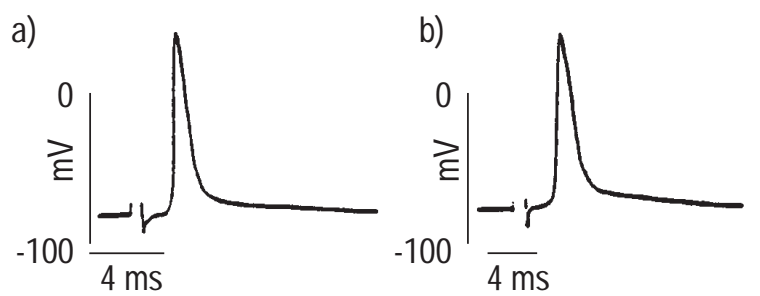

C)

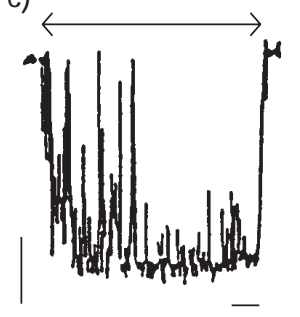

d)
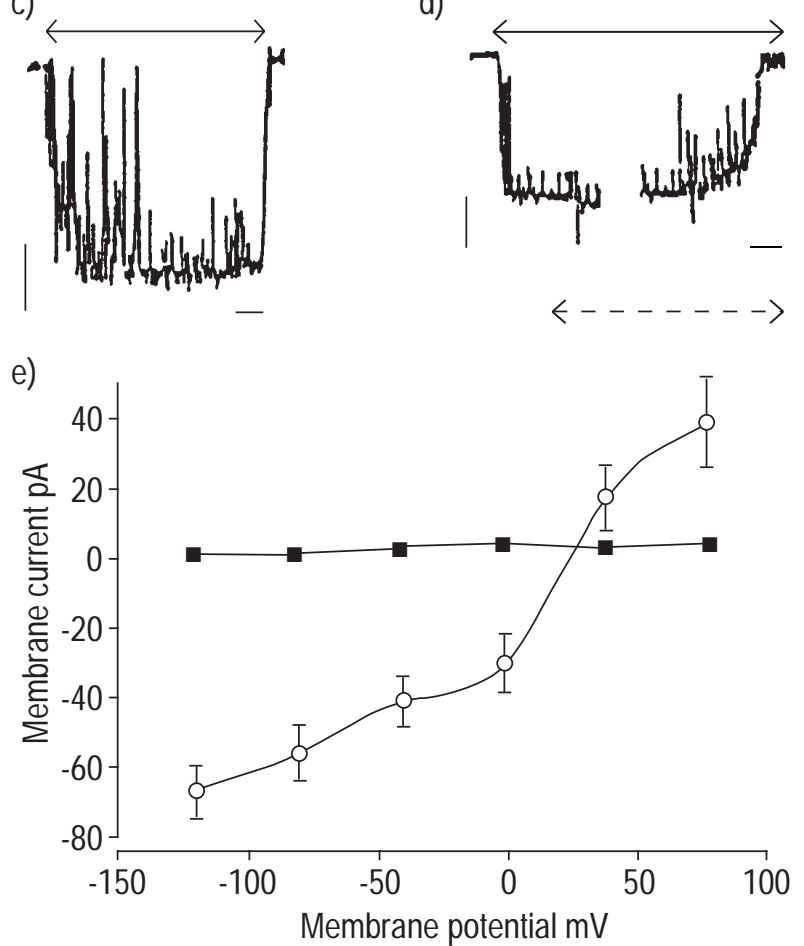

Fig. 2. - Effects of $\mathrm{Gd}^{3+}(50 \mu \mathrm{mol})$ on transmembrane potentials and stretch-activated current in hamster diaphragm muscle. a and b) typical evoked action potential recorded before (a) and after (b) $\mathrm{Gd}^{3+}$ application. c and d) membrane current obtained on a single muscle fibre under a $0 \mathrm{mV}$ pipette potential and during the application of $-20 \mathrm{mmH}_{2} \mathrm{O}$ stretch pulse (E; - - - > d duration of the stretch pulse). Inward currents are shown downward. Vertical scale: $20 \mathrm{pA}$; horizontal scale: $2 \mathrm{~s} . \mathrm{c}$ ) physiological solution. d) physiological solution before and after addition of $50 \mu \mathrm{mol} \mathrm{Gd} \mathrm{G}^{3+}$ inside the patch pipette (---). The interruption of the trace corresponded to $90 \mathrm{~s}$. e) current-voltage relationships of the membrane current obtained in physiological solution before $(O)$ and after $(\square) 50 \mu \mathrm{mol} \mathrm{Gd} d^{3+}$ application. The current was elicited by a stretch pulse $\left(-20 \mathrm{mmH}_{2} \mathrm{O} ; 4 \mathrm{~s}\right.$ duration) applied at different pipette potentials. Resting potential was assumed to be $-80 \mathrm{mV}$ (see Methods). Values are mean \pm SEM ( $n=6$ fibres).

\section{Effects of nifedipine and changes in extracellular ion composition}

The effects of reduced $\left[\mathrm{Na}^{+}\right]_{\mathrm{e}}$ or $\mathrm{Ca}^{2+}$-free medium on length-AT (groups 5-7) are depicted in figure 4. Upon reduction of $\left[\mathrm{Na}^{+}\right]_{\mathrm{e}}$, there was a downward shift of the relation between initial length and active tension (fig. $4 \mathrm{a}$ ). Moreover, the effect of reduced $\left[\mathrm{Na}^{+}\right]_{\mathrm{e}}$ on AT was lengthdependent $(\mathrm{p}<0.05)$, the absolute decrease in AT predominating at shortest initial muscle lengths (fig. 4b). Conversely, the relation between $\mathrm{Li}$ and AT did not change in $\mathrm{Ca}^{2+}$-free solution (fig. 4c) nor after nifedipine addition (fig. 4d).
Table 1. - Effects of gadolinium $\left(\mathrm{Gd}^{3+}\right)$ on transmembrane potentials recorded in diaphragm muscle fibres

\begin{tabular}{lcc}
\hline & Control & $50 \mu \mathrm{mol} \mathrm{Gd}$ \\
\hline RP mV & $-85.9 \pm 0.7$ & $-86.5 \pm 1.1$ \\
OS mV & $33.9 \pm 2.1$ & $30.1 \pm 1.6$ \\
APD0 ms & $0.61 \pm 0.02$ & $0.61 \pm 0.02$ \\
APD5 ms & $4.1 \pm 0.2$ & $4.8 \pm 0.2$ \\
$V_{\max V \cdot \mathrm{s}^{-1}}$ & $2277 \pm 42$ & $2411 \pm 65$ \\
\hline
\end{tabular}

RP: resting membrane potential; OS: overshoot; APD0: duration of the action potential (AP) measured at $0 \mathrm{mV}$; APD5: the duration of the AP measured at a membrane potential $5 \mathrm{mV}$ above the RP; and $V_{\text {max }}$ : first derivative of the initial depolarizing phase. Values are mean \pm SEM $(n=16$, obtained from five muscles). $\mathrm{Gd}^{3+}$ did not significantly modify the characteristics of AP.

\section{Discussion}

This study indicated that $\mathrm{Gd}^{3+}$ downward shifted the relation between $\mathrm{Li}$ and tetanic AT of adult hamster diaphragm muscle in a concentration-dependent manner. As $\mathrm{Gd}^{3+}$ is the most potent blocker of stretch-activated channels $[8,12]$, this is the first report to document that stretch-activated membrane channels operate at physiological muscle stretch and contribute to length-dependent changes in diaphragm contractility. In hamster diaphragm, it is also suggested that these effects can de mediated, at least in part, via increased $\mathrm{Na}^{+}$influx and modulation of intracellular cAMP content.

Electrophysiological recordings in cultured chick and mouse muscle cells have provided evidence that skeletal muscle membrane contains ion channels that are activated by membrane stretching [5, 6]. Consistently, the current observations of isolated diaphragm muscle fibres showed that the membrane generated a current in response to stretch (fig. 2). This current was modulated by the amplitude of the force applied, exhibited marked voltagedependency, and was sensitive to $\mathrm{Gd}^{3+}$, as previously reported for stretch-activated channels from both muscle $[5,6,7,9]$ and nonmuscle [12] membranes. Thus, these experiments support the existence of stretch-sensitive channels within the membrane of diaphragm muscle in the adult hamster. This result was a prerequisite for further mechanical experiments.

It was found that $\mathrm{Gd}^{3+}$ reduced tetanic $\mathrm{AT}$ in a concentration-dependent manner (fig. 1). This is consistent with a report that lanthanide ions inhibit the optimal twitch tension of toad skeletal muscle fibres [19]. $\mathrm{Gd}^{3+}$ is membrane impermeable $[19,20]$. It is therefore thought to exert its effects by acting on the membrane, with no direct action on the sarcoplasmic reticulum or contractile proteins [20].

In striated muscle, mechanosensitive ion channel activation leads to cation influx [5,9-11]. In the current study, $\mathrm{Ca}^{2+}$ influx from the extracellular space did not seem necessary for stretch-induced modulation of the diaphragm length-AT relationship (fig. 4). This is consistent with the notion that the contractile force of adult skeletal muscle is largely independent of $\mathrm{Ca}^{2+}$ influx from the extracellular space and mainly dependent on $\mathrm{Ca}^{2+}$ release from intracellular stores, especially the sarcoplasmic reticulum $[21$, 22]. Conversely, reduced $\left[\mathrm{Na}^{+}\right]_{\mathrm{e}}$ mimicked the effects of $\mathrm{Gd}^{3+}$ on the relation between initial length and active 

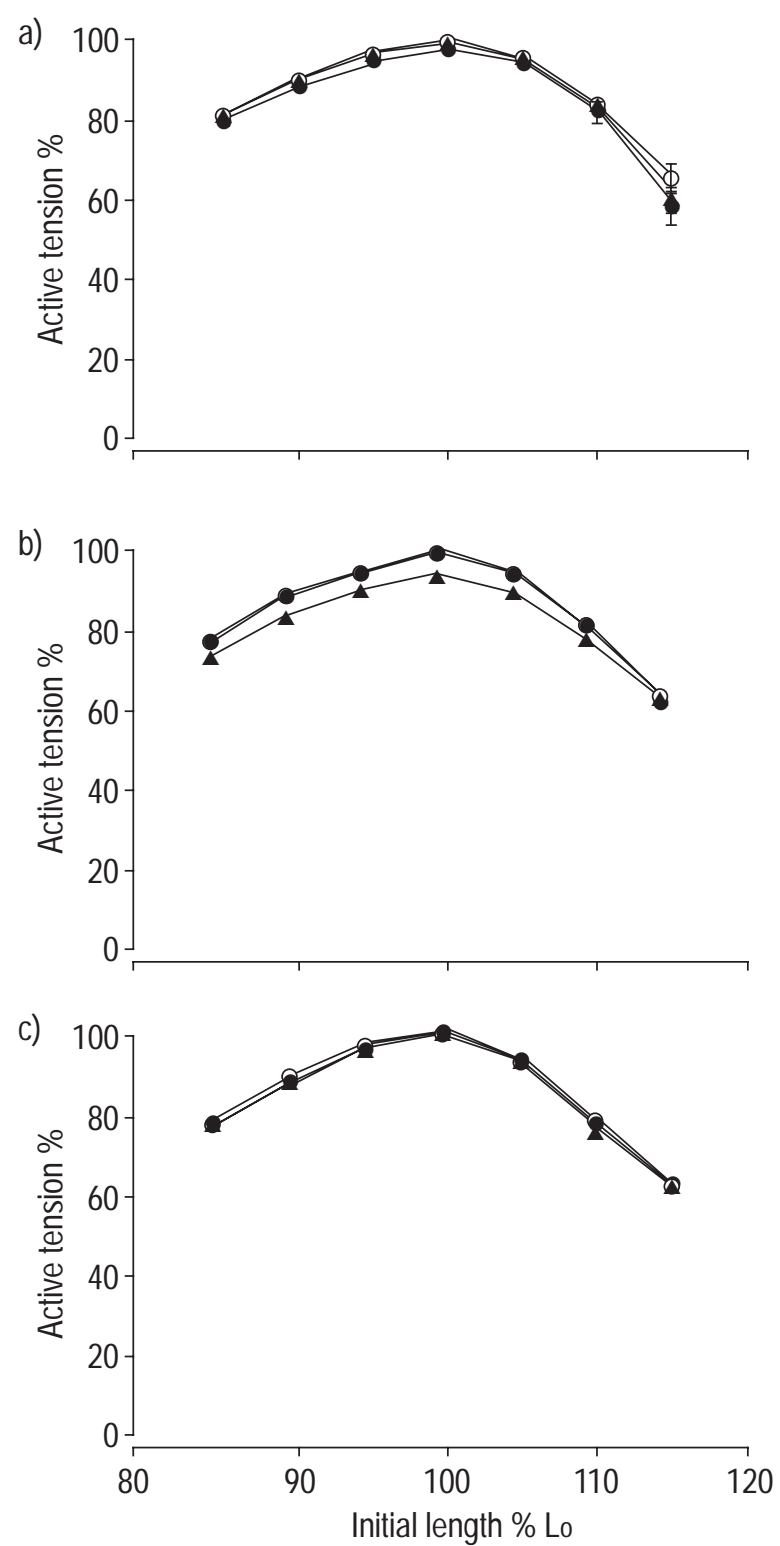

Fig. 3. - Effects of pretreatment with isoproterenol forskolin, dibutyryl cyclic adenosine monophosphate (dcAMP) on $\mathrm{Gd}^{3+}$-induced modulation of the relation between initial length and active tension. Pretreatment of diaphragm muscle with 1 nmol isoproterenol $(a ; n=10), 0.5$ umol forskolin $(\mathrm{b} ; \mathrm{n}=6)$, or $0.1 \mathrm{mmol}$ dcAMP $(\mathrm{c} ; \mathrm{n}=10)$ prevented the effects of $50 \mu \mathrm{mol} \mathrm{Gd}{ }^{3+}$ on the relation between initial length and tetanic active tension. Values are mean \pm SEM. a) $\bigcirc$ : baseline; $\boldsymbol{\Delta}: 1 \mathrm{nmol}$ isoproterenol; $1 \mathrm{nmol}$ isoproterenol $+50 \mu \mathrm{mol} \mathrm{Gd} d^{3+}$, b) $\bigcirc$ : baseline; : $0.5 \mu \mathrm{mol}$ forskolin; $\mathbf{\Delta}: 0.5 \mu \mathrm{mol}$ forskolin $+50 \mu \mathrm{mol} \mathrm{Gd}{ }^{3+}$, c) $\bigcirc$ : baseline; $0.1 \mu \mathrm{mol}$ dcAMP; $\mathbf{\square}: 0.1 \mu \mathrm{mol} \mathrm{dcAMP}+50 \mu \mathrm{mol} \mathrm{Gd}{ }^{3+}$. Lo: optimal muscle length.

tension (fig. 4a). One possibility is that decreased $\mathrm{Na}^{+}$ influx and/or blockade of stretch-sensitive channels reduces the amount of $\mathrm{Ca}^{2+}$ released from the sarcoplasmic reticulum, thus reducing diaphragm tension. Given that the effects of lowering activating $\mathrm{Ca}^{2+}$ predominate at short sarcomere length [23], reduction in diaphragm tension is expected to predominate at short muscle length. This was verified in our study where the depressive effect of $\mathrm{Gd}^{3+}$ was more pronounced at $85 \%$ Lo than at lengths above Lo (fig. 1b). Another possibility was that the gre- ater depressant effect of $\mathrm{Gd}^{3+}$ at lower lengths reflected the sigmoid relationship between stretch-activated channel open probability and stretch $[4,12]$. When the strip is held at lengths between 85 and $100 \%$ Lo, the stretch on the fibre membranes could be in the range where the relationship is steep, while beyond this length the flat top is reached and no extra current flows.

Mechanical stretch has been reported to increase cAMP content $[24,25,26]$. This results, at least in S49 mouse lymphoma cells, from direct activation of adenylate cyclase by mechanical forces [25]. Moreover, in myocytes from the urinary bladder, dibutyryl cAMP increases the activity of stretch-activated channels [14]. Lastly, the authors have obtained evidence of a complex interplay between the $\beta$-adrenergic pathway and myocardial stretch [26]. These observations led the authors to examine the effects of agents that increase the intracellular cAMP concentration on $\mathrm{Gd}^{3+}$-induced changes in the length-AT curve. The agents chosen (isoproterenol, forskolin and dcAMP) act at different steps in the cascade of events elevating cAMP content [27]. The results showed that isoproterenol, forskolin or dcAMP prevented the effects of $\mathrm{Gd}^{3+}$ on the relation between $\mathrm{Li}$ and AT. These findings strongly suggest that intracellular cAMP content modulated the effects of stretch-activated ion channels.

In the current study, complete blockade of the dihydropyridine $\mathrm{Ca}^{2+}$ current by $5 \mu \mathrm{mol}$ nifedipine [17] did not modify the relation between initial length and tetanic tension (fig. 4d). This suggests that the effects of $\mathrm{Gd}^{3+}$ were not due to inhibition of voltage-gated $\mathrm{Ca}^{2+}$ channels [28]. A selective stretch-activated channel blocker would allow the relative contribution of stretch- and voltageactivated channels to tension development to be quantified more precisely. No such blocker is currently available, and $\mathrm{Gd}^{3+}$ is the most commonly used blocker of stretch-activated channels [8]. Phosphate and bicarbonate buffer systems can interfere with $\mathrm{Gd}^{3+}$, thus reducing the free $\mathrm{Gd}^{3+}$ concentration [29]. This has been suggested as an explanation for false negative conclusions regarding the role of stretch-activated channels in physiological processes [29]. This was not the case in the current study, given that the authors reported effects of $\mathrm{Gd}^{3+}$, a finding consistent with several previous studies [20, 29]. The possibility that low $\left[\mathrm{Na}^{+}\right]_{\mathrm{e}}$ reduces $\mathrm{Na}^{+}$influx through the voltage-gated channels, as proposed in the case of frog skeletal muscle submitted to severe $\left[\mathrm{Na}^{+}\right]_{\mathrm{e}}$ reduction cannot be excluded [30]. However, as compared to the current study, reduction in $\left[\mathrm{Na}^{+}\right]_{\mathrm{e}}$ is markedly higher in the paper by BEZANILLA et al. [30]. The effect of low $\left[\mathrm{Na}^{+}\right]_{\mathrm{e}}$ are probably complex and differences both in species and $\left[\mathrm{Na}^{+}\right]_{\mathrm{e}}$ reduction make interpretation difficult. Finally, some kind of progressive damage or fatigue might occur and contribute to the increasing effect of $\mathrm{Gd}^{3+}$ with concentrations. Convincing evidence that the increasing effect of $\mathrm{Gd}^{3+}$ with concentration was an expression of dose-dependence is as follows: 1) two baseline measurements of the initial length-AT relationship were recorded at a 10-min interval to ensure the stability of the preparation; 2) despite repeated measurements, there were no significant changes in diaphragm contractility in groups 2, 3 and 4 . It thus seems unlikely that progressive damage or fatigue of the muscle strip, if any, would help explain the current results. 

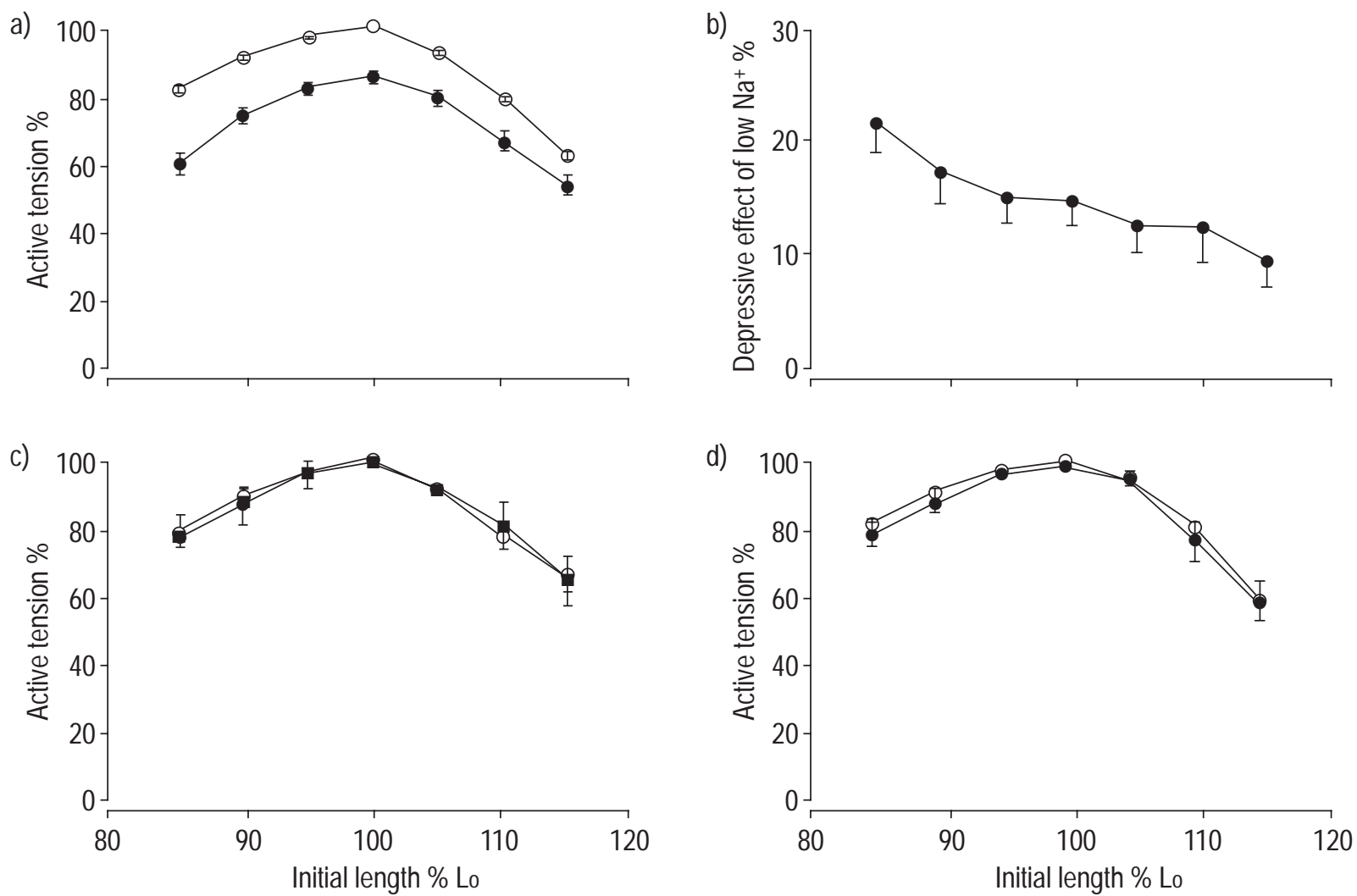

Fig. 4. - Effects of reduced extracellular $\mathrm{Na}^{+}$concentration $\left[\mathrm{Na}^{+}\right]_{\mathrm{e}}$ or $\mathrm{Ca}^{2+}$-free medium on the relation between initial length $(\mathrm{Li})$ and tetanic active tension (AT) of isolated diaphragm muscle from adult hamster. a) $\left[\mathrm{Na}^{+}\right]_{\mathrm{e}}$ is reduced from 142 to 99 mmol. As compared to baseline, reduced [Na $\left.{ }^{+}\right]_{\mathrm{e}}$ $(\mathrm{n}=10)$ down shifted the Li versus AT relationship. b) length-dependent effect of low $\left.\left[\mathrm{Na}^{+}\right]_{\mathrm{e}} \cdot \mathrm{c}\right)$ in $\mathrm{Ca}^{2+}$-free solution ( $\left.\mathrm{n}=6\right)$, no significant changes in the LV versus AT relationship concentration were observed as compared to baseline. d) nifedipine $(5 \mu$ mol; $n=8)$ did not modify the baseline Li-AT relation. Values are mean \pm SEM. a) $\bigcirc$ : baseline; 0 : low $\left[\mathrm{Na}^{+}\right]_{\mathrm{e}}$, c) and d) $\bigcirc$ : baseline; $\mathbf{\square}$ : $\mathrm{Ca}^{2+}$-free; 0 : nifedipine $5 \mu$ mol. Lo: optimal muscle length.

Mechanical forces are sensed and transduced into biochemical signals by multiple pathways, resulting in various biochemical responses [10]. The diaphragm muscle is rhythmically subjected to a variety of mechanical forces in the form of stretch. It is possible that stretch-sensitive channels, among other mechanosensors, participate in the transduction of mechanical stress into regulation of gene expression and protein synthesis. Further studies are needed to elucidate this point.

In conclusion, in adult hamster diaphragm, active tension measured over a range of initial muscle lengths is reduced by gadolinium. This indicates that stretch-sensitive channels are activated in physiological conditions (i.e., when initial muscle length varies) and modulate diaphragm contractility. Experimental conditions leading to increased intracellular cyclic adenosine monophosphate concentrations antagonize the effects of stretch-sensitive channel blockade in the diaphragm.

\section{References}

1. Loring SH, Mead J, Griscom NT. Dependence of diaphragmatic length on lung volume and thoracoabdominal configuration. J Appl Physiol 1985; 59: 1961-1970.

2. Gordon AM, Huxley AF, Julian FJ. The variation in isometric tension with sarcomere length in vertebrate muscle fibres. J Physiol (Lond) 1966; 184: 170-192.
3. Huxley AF. Muscle structure and theories of contraction. Prog Biophys Chem 1957; 7: 255-318.

4. Morris CE. Mechanosensitive ion channel. J Membrane Biol 1990; 113: 93-107.

5. Franco A, Lansman JB. Stretch-sensitive channels in developing muscle cells from a mouse cell line. J Physiol (Lond) 1990; 427: 361-380.

6. Guharay F, Sachs F. Stretch-activated single ion channel currents in tissue-cultured embryonic chick skeletal muscle. J Physiol (Lond) 1984; 352: 685-701.

7. Bialecki RA, Kulik TJ, Colucci WS. Stretching increases calcium influx and efflux in cultured pulmonary arterial smooth muscle cells. Am J Physiol 1992; 263: L602L606.

8. Hamill OP, McBride DW. The pharmacology of mechanogated membrane ion channels. Pharmacol Rev 1996; 48: 231-252.

9. $\mathrm{Hu} \mathrm{H}$, Sachs F. Mechanically activated currents in chick heart cells. J Membrane Biol 1996; 154: 205-216.

10. Kent RL, Hoober K, Cooper IV G. Load responsiveness of protein synthesis in adult mammalian myocardium: role of cardiac deformation linked to sodium influx. Circ Res 1989; 64: 74-85.

11. Sigurdson WS, Ruknudin A, Sachs F. Calcium imaging of mechanically induced fluxes in tissue-cultured chick heart: role of stretch-activated ion channels. Am J Physiol 1992; 262: H1110-H1115.

12. Yang X-C, Sachs F. Block of stretch-activated ion channels in Xenopus oocytes by gadolinium and calcium ions. Science 1989; 243: 1068-1071. 
13. Brown AM, Birnbaumer L. Direct G protein gating of ion channels. Am J Physiol 1988; 24: H401-H410.

14. Wellner M-C, Isenberg G. cAMP accelerates the decay of stretch-activated inward currents in guinea-pig urinary bladder myocytes. J Physiol (Lond) 1995; 482: 141-156.

15. Coirault C, Chemla D, Péry-Man N, Suard I, Lecarpentier Y. Isometric relaxation of isolated diaphragm muscle: influence of load, length, time and stimulation. $J$ Appl Physiol 1994; 76: 1468-1475.

16. Lecarpentier Y, Chemla D, Blanc F-X, et al. Mechanics, energetics, and crossbridge kinetics of rabbit diaphragm during congestive heart failure. Faseb $J$ 1998; 12: 981989.

17. Neuhaus R, Rosenthal R, Lüttgau HC. The effects of dihydropyridine derivatives on force and $\mathrm{Ca}^{2+}$ current in frog skeletal muscle fibres. J Physiol (Lond) 1990; 427: 187-209.

18. Sauviat M-P, Chesnais J-M, Diacono J, Biard J-F, Verbist $\mathrm{J}-\mathrm{F}$. Influence of Bistramide A on the twitch tension in rat atrial heart muscle. Experientia 1994; 50: 926-930.

19. Hambly BD, dos Remedios CG. Responses of skeletal muscle fibres to lanthanide ions. Dependence of the twitch response on ionic radii. Experientia 1977; 33: 10421044.

20. Lab MJ, Zhou BY, Spencer CI, Horner SM, Seed WA. Effects of gadolinium on length-dependent force in guinea-pig papillary muscle. Exp Physiol 1994; 79: 249-255.

21. Armstrong CM, Bezanilla FM, Horowicz P. Twitches in the presence of ethylene glycol bis (-aminoethyl ether)N,N'-tetracetic acid. Biochem Biophys Acta 1972; 267: 605-608.
22. Lüttgau HC, Spiecker WJ. The effects of calcium deprivation upon mechanical and electrophysiological parameters in skeletal muscle fibres of the frog. $J$ Physiol (Lond) 1979; 296: 411-429.

23. Allen JD, Moss RL. Factors affecting the ascending limb of the sarcomere length-tension relationship in rabbit skinned muscle fibres. J Physiol (London) 1987; 390: 119-136.

24. Watson PA, Haneda T, Morgan HE. Effect of higher aortic pressure on ribosome formation and cAMP content in rat heart. Am J Physiol 1989; 256: C1257-C1261.

25. Watson PA. Direct stimulation of adenylate cyclase by mechanically forces in S49 mouse lymphoma cells during hyposmotic sweeling. J Biol Chem 1990; 265: 65696575.

26. Suard I, Péry-Man N, Coirault C, Pourny J-C, Lecarpentier Y, Chemla D. Relaxant effects of isoproterenol in isolated cardiac muscle: influence of loading patterns. $\mathrm{Am}$ J Physiol 1994; 267: H1814-H1823.

27. Daly JW. Forskolin, adenylate cyclase, and cell physiology: an overview. Adv Cyclic Nucl Prot Phosphor Res 1984; 17: 81-89.

28. Biagi BA, Enyeart JJ. Gadolinium blocks low and high threshold calcium currents in pituitary cells. Am J Physiol 1990; 259: C515-C520.

29. Caldwell RA, Clemo HF, Baumgarten CM. Using gadolinium to identify stretch-activated channels: technical considerations. Am J Physiol 1998; 275: C619-C621.

30. Bezanilla F, Caputo C, Gonzalez-Serratos H, Venosa RA. Sodium dependence of the inward spread of activation in isolated muscle fibres of the frog. J Physiol (London) 1972; 223: 507-523. 